DOI: 10.1515/ausfm-2016-0010

\title{
Indexicality or Technological Intermediate? Moving Image Representation, Materiality, and the Real
}

\author{
James Verdon \\ Swinburne University of Technology (Australia) \\ E-mail: jverdon@swin.edu.au
}

\begin{abstract}
Drawing on the application of C. S. Peirce's notion of indexicality, this paper argues that iterative imaging technologies modulate the manner in which moving images represent reality and determine how they are traced back to that referent. Rather than subscribing to the canonical divergence between analogue and digital technologies, the paper argues that current moving image theories do not sufficiently acknowledge the granularity of technology when describing indexical relationships between moving images and the reality they represent. Despite a shared use of analogue technologies, film's technique of fixing a full frame of movement to a momentarily static strip of light-sensitive celluloid or Mylar is profoundly different from analogue video's parsing of the image frame to its constituent parts and then recording this signal to continuously moving tape or broadcasting the resulting images. These are particularities of technique and technology, not easily ranked in terms of verisimilitude. The paper concludes that despite a widely accepted indexical analogue/digital divide, the indexical status of analogue video is no different to that of digital video images because both consist of discrete and non-continuous picture elements.
\end{abstract}

Keywords: C. S. Peirce, indexicality, reality, analogue video, imaging technologies.

\footnotetext{
"What we are seeking to explain or understand, very broadly speaking, are the moving image screen or screens, what is displayed on these screens, and the nature of our encounter with them. In thinking about these things, we may focus variously on the screen itself, on our mental processes, on our bodies, or on the heterogeneous 'surround'. This is a wide-ranging remit. Moreover, what we are seeking to understand or explain is not only diverse but also in a process of changing and becoming” (Kuhn 2009, 5-6).
} 


\section{Introduction}

The evolution of imaging technologies is a central instigator of Kuhn's "becoming" and the representation of reality is central to studies of the moving image. The status of mimetic relationships between moving images and reality is often premised on a divide between analogue and digital technologies. The conversion of continuous reality into binary numerical values - the digital, irrevocably mutates the "real" world into a less verisimilitudinous representation of the reality it depicts (Mulvey 2004; 2006; Stewart 2007; Elsaesser 2009).

I argue that claims of a metamorphosis requiring digitisation overlook the role, processes, and contribution of analogue electronic moving images to this transfiguration. Enduring articulations made about the relationship between moving images and reality are often anchored in notions of indexicality, the term referring to a single class of signs defined by Charles Sanders Peirce. Peirce's notion of the index is concerned with mediation and more specifically, identification through relational signs. Within a metonymic framework it attempts to describe the relationship between signs and their referents - "objects" in Peircian terms. Rudolph Arnheim succinctly summarises this relationship as "the object does not only resemble reality but is a product of it - mechanical reproduction" $(1957,27)$.

Manovich (1999; 2001) writes of the material origin of digital images and how they ignore lineage, that a photograph, a computer generated image, and digital 2D hand drawn animations are digitally indistinguishable from each other. Mulvey (2006) argues that the viewer's ability to break the flow of motion in digital moving images by pausing a DVD-Video for example is a rationale for this severance. Even Rodowick, who attempts to present a balanced view, characterises the shift from analogue to digital "as a one-way street in which the causal link to physical reality becomes weakened or attenuated," eventually conceding a "discontinuity" $(2007,118 ; 120)$. In this paper I clarify how arguments proposing an indexical break for solely digital moving images are heavily weighted toward solely theoretical considerations and that they omit inherent technological properties of moving images, that is, their material form.

\section{Peircian Indexicality}

In making a case for indexical relationships between reality and moving images that is dependent on specific technologies, this paper also offers an alternative alignment to broadly accepted structures that form histories of the moving image. 
This revision pays particular attention to the indexical transformation through technologies of moving images in relation to pro- and a-filmic reality. Much has been made of the indexical relationship between moving images and reality having been altered alongside changes to image making technologies. Rodowick, as noted above, leaves no room for capitulation in his summation, declaring that "because of the discontinuity of inputs and outputs, the force of indexicality in digital-capture devices stops when light falls on sampling devices, whether they be the chargecoupled receptors of digital cameras or the samplers of digital sound recordings. From this moment forward, light and sound become symbols, and therefore manipulable as such" $(2007,120)$. I argue, however, that extant histories of the moving image do not sufficiently acknowledge the subtlety of pivotal technological processes when considering indexical transformations of the moving image.

A Peircian sign represents an object as an Icon, an Index or a Symbol. These classes are part of a larger intricate taxonomy of sign classification that Peirce offers and the trichotomy of Icon, Index and Symbol is one of the earliest and least cumbersome of Peirce's classifications. Peirce revised and added to his typology of signs over numerous published and unpublished papers spanning more than forty years, resulting in a plethora of sign classifications. Burks' and others' studies of Peirce's sign theory reveal inconsistencies, confusions and conflations (Burks 1949, 675; Weiss and Burks 1945; Goudge 1965; Hoopes 1991; Atkins 2005; Short 2007, 207).

This paper concerns only the earliest single trichotomy of categories, reasoning that this is the set of classifications that in various forms is most often referred to by film and media theorists. Burks was part of the first generation of twentieth century philosophers to interpret Peirce's work and much of his criticism of Peirce's arguments naturally do not take into account Peirce's writing published after this time that addresses some of these criticisms (Atkins 2005). There is substantial debate concerning the robustness, exceptions, classifications and logic of Peirce's taxonomies and shifting terminology and much of this detail is extraneous to this paper (Atkins 2005; Short 2007). ${ }^{1}$ This paper deals with Peircian

1 Causality is one of these issues that are extraneous but relevant to indexicality for moving images. Without direct reference to Goudge $(1965,55)$ or Burks $(1949,679-670)$ notable threads of philosophical debate around Peirce's index and the conflation of causality and semiotic relations as demonstrated by Peirce's examples of the weathervane and the North Celestial Pole Star, T. L. Short (2007) for the most part resolves this point. He first quotes the distinction between a Peircian Icon not requiring a causal connection but denoting its object by "virtue of characters of its own which it possesses, just the same, whether any such Object exists or not" (Peirce qtd. in Short 2007, 215). Short then goes on to identify Peirce's definition of indices shifting across multiple papers, noting that Peirce in 1903 characterises an index as "a sign 
Indices as one part of a larger taxonomy and the legacy of that relationship as it has been applied to the moving image. The paper does not undertake an audit or exploration of Peircian semiotics excepting indexicality that has become a trope of representation for photographic imagery in its own right.

Tom Gunning frames this as a reductive approach, arguing that Peirce's index has been "largely abstracted" from its framing taxonomy and treated as simply an "existential trace or impression left by an object" $(2007,30)$. Gunning goes on to argue that "what we might call a diminished concept of the index may have reached the limits of its usefulness in the theory of photography, film, and new media" $(2007,31)$. I agree that the use of a reductive or abstracted notion of the index is problematic. But focusing moving image representation through the lens of successive technologies in combination with accurately portraying Peirce's index presents a more precise reading of the relationship between moving images and reality than has been offered previously.

Additionally, through these benchmarks I challenge the canonical view that a division between analogue and digital technologies forges a necessary Peircian indexical uncoupling.

Peirce's triadic structure of icon, index and symbol are classes that describe how a sign stands in for its referent. Icons represent the object through a quality of the object such as colour. They exhibit a likeness in the way a landscape painting represents that terrain whereas indexes represent the object through an existential and, at times, causal relationship. An analogue photograph is the crucial example from Peirce here - it indicates. Notably, it is also iconic in that it is a likeness and further, is symbolic in that there is a visual language that must be understood to apprehend the photograph as a representation of reality in terms of flatness, scale, colour, and temporal shift. The photograph additionally employs symbols to represent the object (and at times the sign) through accepted use, via a rule or

which refers to the Object that it denotes by virtue of being really affected by that Object". Yet at a similar time, Peirce also defined the index as "a sign [...] which refers to its object not so much because of any similarity [...] nor [by association] as because it is in dynamical (including spatial) connection both with the individual object, on the one hand, and with the senses or the memory of the person for whom it serves as a sign, on the other" (Short 2007, 219). Short concludes that a spatial connection must be between two actualities, existing or occurring, but does not require one to be the cause of the other: "the dynamic relation of index to object depends on the existence of the latter" $(2007,219)$. Even if the causal condition is debatable, "delineating the role that causality plays [in Peirce's index] is not an easy task" (Atkins 2005, 22). The photograph exhibits but does not require causality and so although important to a Peircian taxonomy, the point may be largely put aside in the context of this paper. What remains, however, is the insular quality of Peircian Icons, not requiring causal relationships with their object and not even necessitating their existence. 
usual designation. Signs will be interpreted as such and are general indicators for which meaning is understood through usage, as with books or words.

There are several attributes to an indexical sign including the index forming an inseparable pair with its object, necessitating the object's existence; the object being an individual thing; the index intrinsically showing its object but not describing it; and the relationship being non-rational (Goudge 1965; Atkins 2005). These are all important conditions but the most important attribute of indexicality to this discussion is that an index has a direct physical relationship with its object. This means that for one of the numerous examples Peirce offers the photograph - the relationship between image and reality is one for which the index is pure or genuine. ${ }^{2}$

\section{The Indexicality of Photographs and Moving Images}

From Peirce's descriptions and then interpretations of Peirce's writings, it can be argued in a non-contentious fashion that film-based photographs - both still and moving - have an indexical relationship with the pro- or a-filmic reality they depict. This is primarily, but importantly not a necessary attribute of indexicality, because of the causal nature of photographic representation. The light falling on the filmic substrate that records the images is shared with the light illuminating the depicted scene. There is a direct and physical relationship between the image recorded and the reality it represents. The light that inscribes the latent filmic image and so allows the viewer to see a resultant image is the same light that allowed the Peircian Object to be discerned.

Three valorised twentieth century film theorists make links between still photography and the moving image as having the same photochemical base and recording images in much the same fashion. André Bazin (1960) famously

2 The photograph, given by Peirce as an example of a Second and having a corresponding indexical relationship with the reality it depicts, can be observed to also have qualities of Firstness and Thirdness - iconicity and symbolism. These are not as important as the qualities of Secondness however. The general iconic resemblance that the photograph has to the scene depicted and the shared symbolic understanding of the visual language enabling the photograph to be read as a representation of the scene depicted is subsumed, in terms of the relational status between the indexical sign and Object, by the indexical relationship that exists between them. In Peircian taxonomy, a photograph as index may have an icon incorporated within it and similarly, a symbol may have an icon or index incorporated within it. Further, the object must be a particular thing in Peircian taxonomy and so a photograph as a first or an icon, exhibits a likeness that cannot be said to be only a likeness of that particular object. Peirce holds that only indexical relationships can be formed with particular objects (Short 2007, 215). The iconicity possible within photographs however, is central to the relationship that digital, rather than analogue, images have with their Peircian objects. 
argues for the mechanical origins of photography as offering an objective view of the depicted scene and his contribution to representations of the real in cinema continues to influence theoretical discussions of cinematic realism. Bazin's argument, similar to Panofsky's (1997), which considers the proximity of still photography and the moving image against other forms of representations, is useful here in establishing an essential link between photography and the moving image: "painting was forced, as it turned out, to offer us illusion and this illusion was reckoned sufficient unto art. Photography and the cinema on the other hand are discoveries that satisfy, once and for all and in its very essence, our obsession with realism [...] for photography does not create eternity, as art does, it embalms time, rescuing it simply from its proper corruption. Viewed in this perspective, the cinema is objectivity in time. The film is no longer content to preserve the object, enshrouded as it were in an instant, as the bodies of insects are preserved intact, out of the distant past, in amber. The film delivers baroque art from its convulsive catalepsy. Now, for the first time, the image of things is likewise the image of their duration, change mummified as it were. Those categories of resemblance which determine the species photographic image likewise, then, determine the character of its aesthetic as distinct from that of painting” (Bazin 1960, 7-8).

Siegfried Kracauer (1997), reviving a predominantly early $20^{\text {th }}$ century concern with the specificity of film and building on his earlier writings on still photography, writes of the filmic image as being an extension of photography. For Kracauer, the value of the moving image is its ability to record and show reality. He writes of moving image indexicality as not only an inscription of reality, as is often cited, but also as a medium that estranges the world it represents. It is the uncanny and the strangely familiar that film promotes through its photographic foundation. This trait has particular resonance with contemporary fantastical representations created through digital technologies presenting hyper-real and impossible photorealistic images.

A third key theorist to notably link the medium of photography with the moving image is Stanley Cavell. He argues that photography and the moving image share optics as an essential common element: "what Panofsky and Bazin have in mind is that the basis of the medium of movies is photographic, and that a photograph is of reality or nature. If to this we add that the medium is one in which the photographic image is projected and gathered on a screen, our question becomes: What happens to reality when it is projected and screened? That it is reality that we have to deal with, or some mode of depicting it, finds surprising confirmation in the way movies are remembered, and misremembered" $(1979,16)$. 
It is clear that intuitive and compelling materially-based arguments can be made for photographic moving images as sharing the central properties of still photography and functionally extending these to include motion in creating film, video and less convincingly, digital moving images. It is also clear and noncontentious that for both still and moving images there is an indexical severance when pro- or a-filmic reality is recorded or manipulated digitally. In this paper I use the predominantly mathematical term "discretisation," literally the process of rendering images materially discrete. It is considered in opposition to these images' indications to continuous profilmic reality. In digitally recorded images, the photoreceptors in digital cameras are the first step in a sequence that converts light into the binary ones and zeros often cited as evidence of an indexical break with reality. As part of this process, sampling occurs and the continuous reality recorded is transformed into a data set that is an incomplete or non-continuous recording of the pro- or a-filmic event. ${ }^{3}$

Images created through film, then, clearly have an indexical relationship with reality. Applying the same Peircian criteria, it can also be seen that digital moving images clearly do not have an indexical relationship with reality. This leaves analogue electronic moving images represented by pre-digital video and television and having no direct still-image correlate, as a special case.

It is important to note at this point that criteria for indexicality are made based on an analogue/digital division rather than a mechanical/electronic distinction. Gaut argues typically for this distribution: "but I will say little about it [analogue video] here, since its salient new features relative to traditional film are its capacities for live broadcast, for enhanced image manipulation and for a degree of interactivity. Digital cinema also possesses the first of these features, while taking the latter two to wholly new heights. So for the purposes of exploring differences between cinematic media, digital cinema is a more striking and useful contrast with traditional film than is analogue electronic cinema. My main point of comparison with traditional photographic cinema, then, will be digital cinema" $(2010,10)$.

Mulvey also sets the analogue in relief to digital, writing that "however significant the development of video had been for film, the fact that all forms of information and communication can now be translated into binary coding with a single system signals more precisely the end of an era" $(2006,18)$. I agree and argue that there is impreciseness to the indexicality of analogue electronic

3 Similarly, analogue images that are digitally manipulated also undergo an indexical break for these same reasons, even if subsequently returned to an analogue state as occurs with the Digital Intermediate (DI) process that traditionally commenced and finished with a film print but underwent digital manipulation in-between. 
moving images and that these images do not clearly share all indexical attributes of either the analogue moving images that came before them or the iconicity of the digital images that followed.

As framed above, Peirce's index conventionally occupies a severing role in understanding the shift from analogue to digital moving images near the end of the twentieth century. The transformation of reality into the ones and zeros of binary data to digitally represent the world on screen has been widely accepted as the location of a break in the essential relationship between moving images and the actuality they point toward. This paper refers to that process as a combination of sampling and quantisation that converts continuously variable reality into a finite number of discrete elements. In Digital Signal Processing (DSP) terms the reduction of a continuous time signal to a discrete set of integer values generates what are known as quantisation errors. It is these errors, generated by the absence of a continuous signal, that substantially contribute to an accepted break in an indexical link between digital moving images and reality.

There is a finite proportion of error though and this is measurable because there are a finite number of signal samples. The maximum quantisation error for an analogue to digital conversion is typically less than the error for an equivalent analogue signal (Santina and Stubberud 2007, 48). It is then crucial when considering an indexical break between the moving image and reality to examine not only the transformation processes leading to changes in the inherent qualities of the image, but also the resultant signal and its veracity to the original.

A voltage with a corresponding amplitude value that varies over time can represent both analogue and digital electronic moving images. This amplitude can be perceived as the subjective brightness - based on the measurable luminance - of the recorded scene. Voltage is sourced from the camera sensor that generates a specific value when exposed to varying amounts of light. Sampling for moving images is the measurement of this voltage at discrete intervals, generating discrete values and then reconstituting these signals as a continuous time signal. This marking of regular intervals in order to arrive at a discrete time signal is commonly employed as part of an image digitisation process.

\section{Image Digitisation}

There are broadly four steps in the digitising process. The first is nominated as digitisation. This step is the sampling of grey values on and around a set of points on a grid array. The next step in the sequence is sampling. Here, "sampling means 
that all the information is lost except at the grid points" (Jähne 2005, 246). The third step is reconstruction through an interpolation of the sample points. The process of reconstruction is, then, the inverse of sampling. Most importantly, the results of these operations are still continuous grey values. The values are still part of an analogue signal. They are not yet quantised. One way to describe the difference between a sampled signal and a quantised signal is that the former has a discrete range but can still contain continuous values within that range, whereas the latter always has discrete values within that range. This global process of discretisation is known, confusingly, as "sampling" while the sequence of its constituent parts can be referred to both as "sampling" and "quantisation."4

The final step in digitising analogue moving images is quantisation. This process plots continuous grey value pixels onto a finite number of discrete grey values. Quantisation always introduces errors, as the true value is replaced by one of the quantisation levels. The general aim of quantisation is that no grey value steps (between luminance levels) should be discernible by a human visual system in a similar way that individual pixels are not visible in many digital images without magnification despite those images not being continuous.

Considering the inherent material forms of the moving image from an engineering perspective, the term "sampling," often referred to as breaking an indexical link between moving images and reality, can be more correctly referred to as quantisation with the sampling stage of the process preserving a continuous signal that is the benchmark for an indexical link with its Peircian object. This use also stems from the global process being colloquially referred to as "sampling."

The use of the term "sampling" to describe the transition from analogue to digital moving images is not only arguably incorrect but more importantly to this discussion, is not just an issue of language. Simply replacing instances of "sampling" with "quantisation" does not negate this problem. Longstanding and widely accepted arguments regarding the process of transformation from analogue to digital moving images cannot be resolved by referring to quantisation rather than sampling because of the fundamental differences between these processes and the materiality of the moving images they are applied to. Similarly, qualifying the term "sampling" as referring to both sampling and quantisation does not account for the analogue output of the constituent sampling phase of the global sampling process. Broad references to "sampling" that ignore the

4 The term "sampling" employed here is distinct from the optical engineering terms "measurement sampling," "analysis sampling” and "display sampling” (Brady 2009, 253-255). Here, "sampling refers to both the process of drawing discrete measurements from a signal and the representation of a signal using discrete numbers” (Brady 2009, 255). 
analogue output of the constituent sampling process have become fundamental assumptions in theorising the effect that digital technologies have on the moving image and the subsequent relationship such images have with reality.

Added to this is the issue of sensor sampling and the indexical status it then confers on analogue images and their subsequent indexical relationship with reality. As Jähne notes, "sampling may already occur in the sensor that converts the collected photons into an electrical signal. In a conventional tube camera, the image is already sampled in lines, as an electron beam scans the imaging tube line by line" $(2005,243)$.

\section{Discretisation and Continuity}

Bill Mitchell's view in a footnote to his description of digital images is in agreement with much other commentary on this point. He introduces explicitly his position on the distinction between analogue and digital images: "It is important to distinguish carefully between analog and digital electronic images. Video images are analog, not digital. Although video images are subdivided into a finite number of horizontal scan lines, the variations in intensity along scan lines are represented by a continuously varying signal” (Mitchell 1992, 228).

My issue with Mitchell's (1992) argument, however, is that, as Jähne (2005) notes, the "continuously varying signal" may be a sampled one. The distinction between sampling and quantisation is again brought to the fore. Whether a sampled image that retains some continuity but with a reduced range of values (rather than an image that is quantised and clearly iconic rather than indexical) is sufficient to maintain an indexical link with its referent object is not clear.

This vexing problem of indexicality for specifically analogue electronic images continues to present a conflicted status when determining what distinguishes electronic analogue moving images from digital images. It is clear that representations of electronic analogue moving images are subject to reduction and approximation i.e. "sampling," in similar ways to digital images but without quantisation.

The engineering proofs of the argument that sampling occurs when creating analogue video images are found in the specifications for analogue video signals as prescribed by the Society of Motion Picture and Television Engineers (SMPTE) standards (SMPTE 1998; 2004). There are a finite number of vertical lines for image recording and display and a specified scanning rate, alternately scanning odd and even lines of the raster image and a limited colour palette as confirmed by Jähne (2005), Watkinson (2008), Case (2001), and Poynton (2003). 
Materially, electronic moving images are constituted by two essential components: luminance and chrominance, and it is useful here to confirm the qualities of these components. It is also useful to consider the fixed bandwidth determined for both analogue and digital video images. This is a restriction that renders images spatially and temporally finite through sampling the data used to represent moving images that in turn represent pro- or a-filmic reality.

The SMPTE describes analogue video as follows: "the composite color video signal shall contain an electrical representation of the brightness and color of a scene being analyzed (the active picture area) along defined paths (scan lines). The signal shall also include synchronizing and color reference signals that allow the geometric and colorimetric aspects of the original scene to be correctly reconstituted at the display" $(2004,2)$.

Analogue NTSC Standard Definition video for example, is described as being limited to 525 lines, 59.94 fields per second achieved by a 2:1 interlace with an aspect ratio of 4:3 (SMPTE 1998; 2004; 2006). The colour component of an analogue video image is similarly constrained in that there is a colour palette restricted to specific display values by virtue of needing to be addressed on the fixed array of a raster display. These bandwidth parameters restrict the brightness, range and intensity of colour stored and displayed.

A dichotomy between continuous and discrete then, is widely considered to be the distinguishing feature when comparing analogue with digital images. The process of digital imaging can record and display greater veracity than its analogue counterpart; it has a larger spatial and temporal resolution; better colour fidelity; and greater exposure latitude, all resulting in superior perceptual realness. These, however, are not the measures employed for Peircian indexical fidelity. The distinction between analogue and digital moving images is emblematically argued by Berys Gaut as being one in which "an analogue image is one that is completely specifiable only by continuously varying values. Object-generated, handmade, photochemical images and pre-digital video images are all analogue. In contrast, a digital image is one composed of discrete values, typically integers" (2009, 76; 2010, 9; 14). Rodowick correspondingly, but subscribing to a causality approach at odds with Short (2007) and Atkins (2005), argues that analogue and digital images may be "qualitatively distinguished according to the types of causation involved in the acquisition of images and by ascertaining whether the causal relations between inputs and outputs are continuous or discontinuous. Here (analogical) transcription should be distinguished from (digital) conversion or calculation" $(2007,116)$. Regardless of Gaut's or Rodowick's positions 
regarding the causality argument, continuity and discreetness are agreed to be the key criteria defining the indexical status of images.

Attending to the SMPTE prescriptions, however, it can be seen that arguments relying only on a rationale of discretisation are problematic when considering an indexical distinction between analogue and digital images. With reference to the SMPTE data and excepting the reference to integers, Mitchell's introductory description of digital images now reads uncannily like a description of analogue video: "images are encoded [...] by uniformly subdividing the picture plane into a finite Cartesian grid of cells (known as pixels) and specifying the intensity of color of each cell by means of an integer number drawn from some limited range” $(1992,5)$.

\section{Spatial Discontinuity in Analogue Video- Imbrication and Halftoning}

Arguments that locate analogue electronic moving images alongside mechanical filmic images and in opposition to digital images are ironically centred on that which was used to separate video images from the earlier technologies creating film images in the twentieth century. These in turn reflect earlier arguments that differentiate photography from painting and theatre. Analogue video and television are perceived, on the one hand, to render a continuous and faithful recording of reality. This is unlike their digital counterparts that grasp snatches of reality and then sample and compress them into packets of digital data, subsequently throwing out parts of the recorded scene in an often perceptually transparent but always materially destructive manner. On the other hand, analogue video is considered to record continuously but against film's stop-start recording method. (Williams 1990; Cubitt 1998; Spielmann 2008; and Mulvey 2006).

\section{Imbrication}

This argument is premised on what Yvonne Spielmann calls a "lack of fixity" in the video signal $(2008,49)$. Analogue video employs recording of fields in which sequential frames are displayed in an imbricated fashion, mixing images from one frame to the next with upper and lower fields alternately presented on screen. This is contrasted with the filmic image comprising a "fixed motion image of the film [...] tied, at shooting and projection, immovably to the template of a vertical ordering of the single image frames on the filmstrip. Video cancels such demands" (Spielmann 2008, 48). 
Spielmann describes video generating a "flow type of image as an unbroken stream [...] constantly moving [...] express[ing] the flow of electrons" (2008, 47). This description and particularly its language, almost contrarily recasts the syntax used to describe film together with analogue video as continuous, against the discretisation of digital signals. The argument, however, is intended to distinguish television and video from film, not from digital images. In this flow model, it is the film image, not a digital one, that is discrete, with video and television images being contrastingly continuous. This focus on analogue video inadvertently congregates material similarities between film and digital images in a way that is not often considered.

Problematically, this view of analogue video and television as continuous only functions for the reconstituted form of these media. In both storage and editing, video and television are frame-addressed as single images in the same way film and digital images are. A further attribute that links analogue video with digital images is that, unlike video, film's constituent parts, excluding latency, remain the same in all states. Film is formed from photo-chemically integrated frames. ${ }^{5}$ Analogue video, television, and digital images all share the attribute of smaller distinct constituent parts forming the screened image, with the deconstructed forms delineated from the constituted image in materiality and appearance. This can be regarded as an electronic form of latency, a term more often associated with the mechanical photographic image. What is useful in this and other iterations of the continuous video model is that the distinctions being made by Spielmann (2008) are between mechanical and electronic technologies, not between analogue and digital ones.

In arguing for a continuous temporal flow for video, an unacknowledged spatial discontinuity is realised through Spielmann's argument. The construction of the imbricated video frame that aims to reduce flicker and the bandwidth required to present the image is at once required for temporal continuity, but at the same time prompts a spatially discontinuous video image by breaking the frame into multiple discretely addressed odd and even fields. As Spielmann concludes but without conceding this point: "this makes it clear that the 'video image' essentially

5 The latency of film can be argued to affect only its exposure or alternately it can, I believe, be more strongly argued that photochemical processing does alter the material form of the film stock, as does any film contact printing. This questions the veracity of the relationship between photographic negatives and prints for still imaging and contact printing for motion images. It could be argued that this positions a recording camera obscura or daguerreotype or ambrotype, for example, as more direct forms of representation than the analogue camera and imaging technologies that followed. 
represents an incomplete and discontinuous type of image” $(2008,49)$. So, the essential temporal continuity created and required by analogue video's raster scanning process inherently instigates a spatial discontinuity by demanding discrete interlaced fields within each video frame. The frame is no longer whole or continuous - no longer indexical - despite being an analogue image.

Although both analogue video and digital media are formed from segmented parts, the nonlinearity of the digital, what Spielmann nominates as "optionality" (2008, 49), differentiates it from its analogue counterpart and it is this rather than Mitchell's (1992) or Spielmann's continuity that provides a tangible material distinction. However, this is only one of many effects available to digital media. Crucially, it is as effortless for digital moving images to operate linearly as nonlinearly.

\section{Halftoning}

There is a further spatial discontinuity inherent within analogue video displays and this second discretisation is more pronounced than above. It is the spatial discontinuity created by filtering the video image as it reaches the phosphor coating positioned at the cathode ray screen. To better understand this effect, I propose a comparison with halftone images [Fig. 1]. Analogue halftones were first developed in the mid-nineteenth century and can be readily seen in a variety of historical and contemporary non-photographic (non-continuous) printed images.

These images can be regarded as instances of sampled photographs. Halftones are the product of converting continuous tone images into images made up of different sized dot patterns or different intervals between dots of the same size to create the effect of continuous grey tones, usually for printing. ${ }^{6}$ Halftones then are discontinuous in that a halftone dot-screen filters the pictorial content, using only a subset of the image elements and discarding others. Halftones are examples of discrete, rather than continuous, analogue images. Under a Peircian framework, halftones do not have an indexical relationship with their referent objects because they are not photographic, not continuous, despite a cursory visual appearance of continuous tone and one of their primary uses being the reproduction of photographs.

There is a strong similarity between the process of generating images through halftone printing and through analogue video. A conventional analogue video

6 There are also digital halftones that achieve similar halftone effects but do so through dithering algorithms. This technology is distinct from analogue halftoning and is not considered here. For more on digital halftoning see O’Quinn and LeClair (1996, 280-294). 
monitor is based on the hardware of a Cathode Ray Tube (CRT). These devices have a shadow mask or an aperture grill at the receiving end of the tube that filters the received light and maps it onto the screen [Fig. 2]. ${ }^{7}$

A shadow mask is a sheet of perforated metal placed just behind the phosphorcoated glass at the front of the screen. It functions as a filter to refocus the light from three electron guns that are activating the individual phosphor dots on the screen, each aligned to particular colours by a triadic arrangement of lightsensitive dots. The differing angles of the guns, as they are most often physically separated at the back of the tube, mean those lights pass through the mask holes at slightly different angles and so only reach the appropriate colour-sensitive target. These dots then, arranged in a triangular form, each receive only light from one of three electron guns. ${ }^{8}$

To achieve a similar effect, the aperture grill (or tension mask) system uses a fine mesh of vertical wires to separate the different colours into vertical strips rather than the triangular arrangement of the shadow mask solution. Aperture grill CRTs can produce brighter images because of a design that allows more light to pass through the mask but are also susceptible to light bleed between the slots, creating a softer image. Shadow mask screens offer more edge definition because of the smaller apertures concentrating light for additional sharpness but have to increase the electron beams' strength to compensate for the light lost outside of the tiny apertures.

The visual and procedural similarities between the screening mesh for analogue printed halftones and electronic analogue screens, requiring some kind of aperture grill or shadow mask, are arresting. The photograph as source image for the printed halftone is akin to the video signal as recorded to be displayed on a CRT. Both display technologies feature discrete picture elements - analogue pixels - which reconstruct a representation of the original continuous tone image in a discrete fashion. Both techniques sample a continuous tone image and present a discretised photographic representation of their referential Peircian object.

7 This is not to be confused with the either a spatial aperture effect in which the electron beam - having a finite radius, exhibits a Gaussian distribution of energy across its diameter or a temporal aperture effect that can introduce a time-lag as the image is scanned right to left, top to bottom. See Watkinson (2008, 77-79) for an introduction to these effects. The spatial aperture effect is related to the overall envelope of the image, effectively limiting the bandwidth of the image but not affecting continuous values within that envelope.

8 For a historical account of the introduction of shadow masks to television in the late 1940s and early 1950s, see Abramson (2003, 40-42). 


\section{Conclusion}

It is evident that confusion exists between sampling and quantisation as criteria for establishing Peircian indexicality for moving images. Underpinning this is the notion that the key attribute of indexicality is continuity with a Peircian object. It is also evident that there are two discontinuities present in analogue video. The first of these is the breaking of continuous video frames into discrete spatial fields as part of the electronic process of generating analogue video images and then an imbrication of these fields in display. The second discontinuity is a halftone-like spatial sampling of the video image resulting in discrete analogue pixels on-screen.

In Peircian terms, either of these ruptures is sufficient to sever an indexical relationship with the image's referent object. This is despite these being analogue photographic images. In strong contrast to a canonical analogue/digital divide regarding indexicality, the indexical status of analogue video imagery is no different to that of digital video images because both fundamentally consist of discrete or non-continuous picture elements: pixels. It is crucial that an enquiry framework examining the indexicality of moving images accounts for differing technologies of representation rather than a less granulated analogue/digital divide as predominantly occurs now.

An indexical break between automated moving images and reality does not first occur historically as part of the transformation from analogue to digital moving images in production and reception but through the transformation from images mechanically rendered to those analogue electronic images experienced as video and television, decades prior to the introduction of digital imaging.

\section{References}

Abramson, Albert. 2003. The History of Television, 1942 to 2000. Jefferson: McFarland \& Company.

Arnheim, Rudolf. 1957. Film as Art. Los Angeles: University of California Press. Atkins, Albert. 2005. Peirce on the Index and Indexical Reference. Transactions of the Charles S Peirce Society vol. 41. no. 1: 161-188.

Bazin, André. 1960. The Ontology of the Photographic Image. Film Quarterly vol. 13. no. 4: 4-9.

Brady, David Jones. 2009. Optical Imaging and Spectroscopy. Hoboken: John Wiley \& Sons and The Optical Society of America. 
Burks, Arthur W. 1949. Icon, Index and Symbol. Philosophy and Phenomenological Research vol. 9. no. 4: 673-689.

Case, Dominic. 2001. Film Technology in Post Production. Burlington: Elsevier. Cavell, Stanley. 1979. The World Viewed: Reflections on the Ontology of Film. Cambridge: Harvard University Press.

Cubitt, Sean. 1998. Digital Aesthetics. London, Thousand Oaks, New Delhi: SAGE Publications.

Elsaesser, Thomas. 2009. Ingmar Bergman in the Museum? Thresholds, Limits, Conditions of Possibility. Journal of Aesthetics and Culture (online) vol. 1. http://www.aestheticsandculture.net/index.php/jac/article/view/2123. Last accessed 05.06.2016.

Gaut, Berys. 2009. Digital Cinema. In The Routledge Companion to Philosophy and Film, eds. Paisley Livingston and Carl Plantinga, 75-85. Abingdon: Routledge.

Gaut, Berys. 2010. A Philosophy of Cinematic Art. Cambridge: Cambridge University Press.

Goudge, Thomas A. 1965. Peirce's Index. Transactions of the Charles S Peirce Society vol. 1. no. 2: 52-70.

Gunning, Tom. 2007. Moving Away from the Index: Cinema and the Impression of Reality. Differences: A Journal of Feminist Cultural Studies vol. 18 no. 1: $29-52$.

Harward, Tristan. 2007. Shadow mask vs aperture grille. http://commons. wikimedia.org/wiki/File:Shadow mask_vs_aperture_grille.jpg. Last accessed 07.01.2016.

Hoopes, James, ed. 1991. Peirce on Signs: Writings on Semiotic by Charles Sanders Peirce. Chapel Hill: The University of North Carolina Press.

Jähne, Bernd. 2005. Digital Image Processing. Heidelberg: Springer.

Kracauer, Siegfried. 1997 [1960]. Theory of Film: The Redemption of Physical Reality. Princeton: Princeton University Press.

Kuhn, Annette. 2009. 'Screen' and Screen Theorising Today. Screen vol. 50. no. 1: 1-12.

Manovich, Lev. 1999. What is Digital Cinema? In The Digital Dialectic: New Essays on New Media, ed. Peter Lunenfeld, 172-197. Cambridge: The MIT Press.

Manovich, Lev. 2001. The Language of New Media. Cambridge: The MIT Press. Mitchell, William John. 1992. The Reconfigured Eye: Visual Truth in the PostPhotographic Era. Cambridge: The MIT Press. 
Mulvey, Laura. 2004. Passing Time: Reflections on Cinema from a New Technological Age. Screen vol. 45. no. 2: 142-155.

Mulvey, Laura. 2006. Death $24 x$ a Second: Stillness and the Moving Image. London: Reaktion Books.

O’Quinn, Donnie and Matt LeClair. 1996. Digital Prepress Complete. Indianapolis: Hayden Books.

Panofsky, Erwin. 1997. Style and Medium in the Motion Pictures. In Three Essays on Style, ed. Irving Lavin, 93-127. Cambridge: The MIT Press.

Poynton, Charles. 2003. Digital Video and HDTV: Algorithms and Interfaces. San Francisco: Morgan Kaufmann Publishers.

Rodowick, David Norman. 2007. The Virtual Life of Film. Cambridge: Harvard University Press.

Santina, M. S. and A. R. Stubberud. 2005. Basics of Sampling and Quantization. In Handbook of Networked and Embedded Control Systems, ed. Dimitrios Hristu-Varsakelis and William S. Levine, 45-69. Boston: Birkhäuser.

Short, T. L. 2007. Peirce's Theory of Signs. Cambridge: Cambridge University Press.

Society of Motion Picture and Television Engineers. 1998. For Television: ThreeChannel RGB Analog Video Interface. New York: Society of Motion Picture and Television Engineers.

Society of Motion Picture and Television Engineers. 2004. For Television: Composite Analog Video Signal - NTSC for Studio Applications. New York: Society of Motion Picture and Television Engineers.

Society of Motion Picture and Television Engineers. 2006. For Television: Analog Recording: 1/2-in Type M-2 - Electrical Parameters of Video, Audio, Time and Control Code and Tracking Control. New York: Society of Motion Picture and Television Engineers.

Spielmann, Yvonne. 2008 [2005]. Video: The Reflexive Medium. Cambridge: The MIT Press.

Stewart, Garrett. 2007. Framed Time: Toward a Postfilmic Cinema. Chicago: University of Chicago Press.

Watkinson, John. 2008. The Art of Digital Video. Burlington: Elsevier.

Weiss, Paul and Arthur W Burks. 1945. Peirce's Sixty-Six Signs. The Journal of Philosophy vol. 42. no. 14: 383-388.

Williams, Raymond. 1990. Television: Technology and Cultural Form. London: Routledge. 


\section{List of Figures}

Figure 1. Generic analogue halftone screen - magnified.

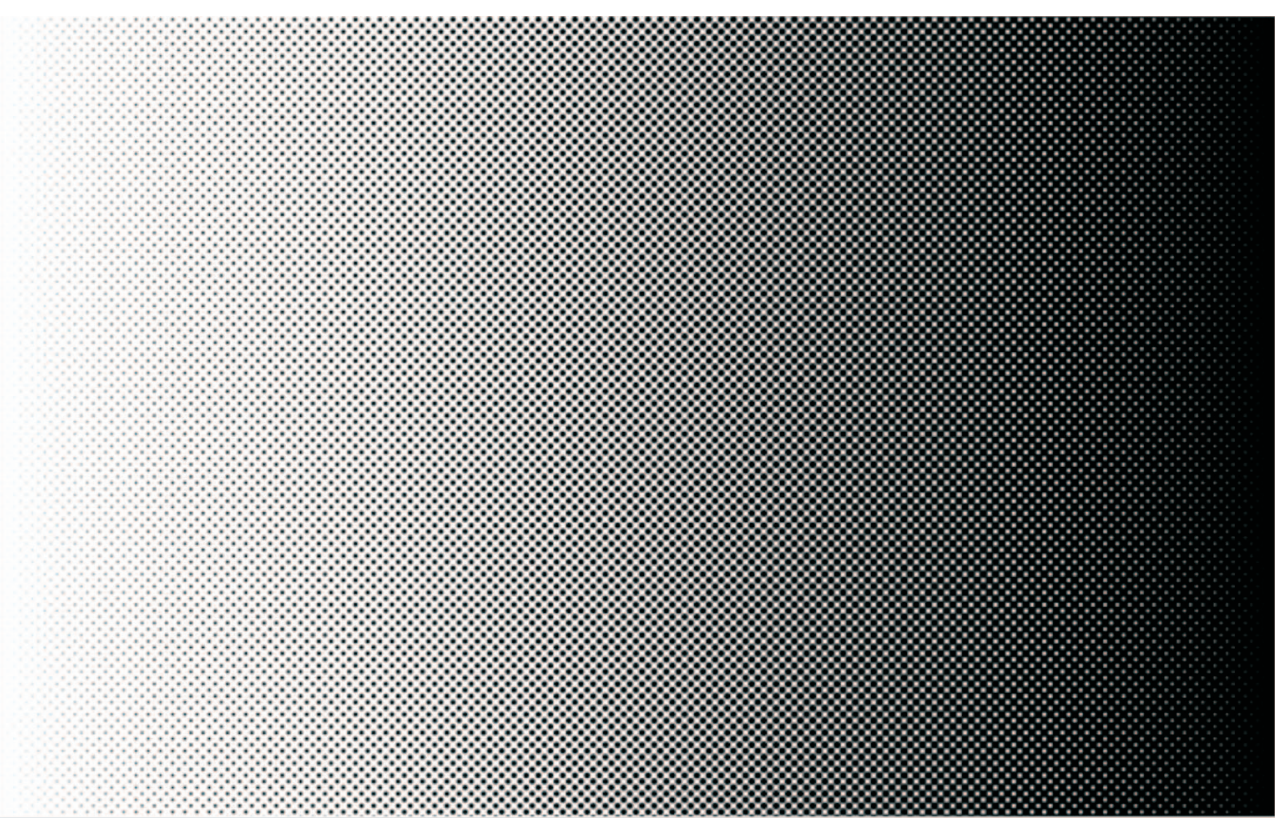

Figure 2. Television shadow mask and aperture grill (Harward 2007).
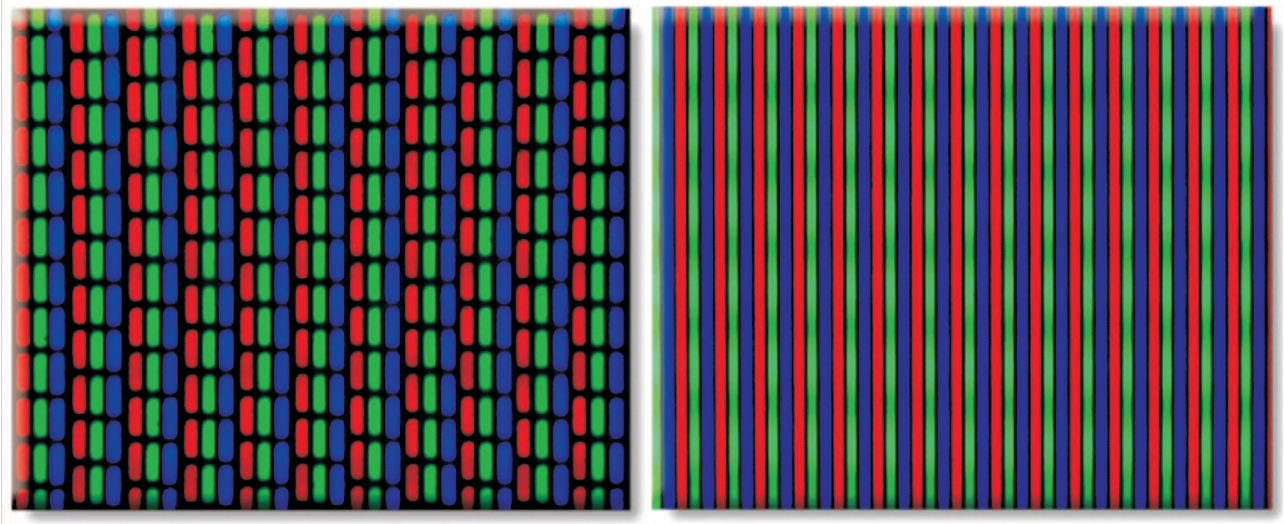